\title{
Nomination vs. election: do they influence women's access to institutional decision-making bodies?
}

\author{
Sara Diogo ${ }^{1,2,3}$ (D) . Teresa Carvalho ${ }^{1,2} \cdot$ Zélia Breda $^{3,4}$
}

Accepted: 24 September 2020 / Published online: 31 October 2020

(c) The Author(s) 2020

\begin{abstract}
Portuguese higher education institutions (HEIs) are excellent case-studies of women representation in academia, considering their significant presence and rapid growth in HEIs. Nevertheless, and despite efforts to minimise gender gaps, women are still underrepresented in top management and leading positions, contributing to increment the phenomenon of vertical segregation. Based on the reality of the Portuguese academia, and focusing on an in-depth case study of a Portuguese university, this paper analyses if and how the way decision-making bodies are constituted, influence the gender balance of their members. Recently, within the New Public Management (NPM) context, HEIs have been subjected to external pressures to create a new organisational environment aiming at substituting the collegial model of governance with a managerial one. In this context, there has been a trend to replace the election by the nomination as the dominant process to occupy decision-making positions. The opening hypothesis of this study is that the way decision-making bodies are constituted, impacts on their gender balance. More specifically, it is argued that the nomination process tends to be more advantageous to women than the election. However, although it is possible to conclude that the gender balance decreases with the increasing importance of the decision-making body, it is not accurate to say that there is a direct relationship between the way actors are chosen to these bodies and their gender balance. In other words, the way actors are chosen can not be seen as the only factor influencing the gender constitution of decision-making bodies. The study provides a relevant contribution to the literature on mechanisms and strategies to improve gender equality in institutional decision-making processes and bodies.
\end{abstract}

Keywords Universities $\cdot$ Managerialism $\cdot$ New public management (NPM) $\cdot$ Gender balance $\cdot$ Governance $\cdot$ Nomination $\cdot$ Election $\cdot$ Decision-making bodies

Sara Diogo

sara.diogo@ua.pt

Extended author information available on the last page of the article 


\section{Introduction}

The lack of women in leadership positions across higher education as a result of the well-known phenomenon of vertical segregation has been problematized in the literature (Bagilhole and White 2011; White et al. 2011; Burkinshaw and White 2017; Carvalho and Diogo 2018b). Vertical segregation is defined by Reskin and Roos (1990) as the tendency to find women's concentrated in clerical and low-level management. In fact, despite the feminization of universities in terms of the number of female students, formal positions in top management and/or leading positions, academic leadership in higher education remains concentrated in male hands (O'Connor 2018; Carvalho and Diogo 2018b; Ryan and Haslam 2005). Additionally, and although the representation of women in leadership roles has increased, this happens mostly in administrative areas (Burkinshaw and White 2017) — at the technostructure level. It is thus this increase in female students, faculty and administrators all over the world that has been touted as gender equity has achieved the University (Alemán 2014). However, leadership is still mostly associated with a men's activity and, according to Dunn et al. (2014), male-centric leadership models and norms have served to limit women's aspirations as well as their access to leadership roles. In Europe, women are underrepresented in leadership positions in all the countries, with its proportion among the heads of higher education institutions standing at 21.7\% in 2017 (EU 2019). Thus, although women have succeeded in entering the academic career they are still excluded from the academic elite, meaning from formal outstanding academic positions ( $\operatorname{Rogg} 2003)$.

In this sense, the underrepresentation of women in academic elite suggests that masculine practices and leadership norms function to exclude women, which is particularly problematic, considering that the underrepresentation of women in decision-making positions in academia (as well as in public life) also represents a waste of talent (Dunn 2012). Being leadership historically and normally assumed by men, discourses aiming at helping women breaking through the "glass ceiling" generally focused or passed the idea that there is a need of "fixing the women", contributing to perpetuate the inexistence of gender-neutral career development, and even to maintain (or deepen) the precariousness of (leadership) careers of female academics (Alemán 2014; Burkinshaw and White 2017). The glass ceiling metaphor is widely used, especially in private corporations, to represent the invisible barriers women face in moving up organisational ladders (Acker 2009; Campbell and Vera 2010; Wieland and Flavel 2015). The reasons limiting women's access to the academic elite have been highly scrutinised. In fact, there is a vast literature reflecting on the barriers women face to access boards. Among them, one can refer to the identification with gender role expectations, the work-family conflict, gender discrimination, performance stereotypes and structural barriers based on institutions behaviour (Eagly and Karau 2002; Powell and Greenhaus 2010; Dunn et al. 2014). However, less attention has been devoted to the influence of the way governance bodies are constituted. This is even more relevant since the mid-1970s, NPM and managerialism call for new ways of 
viewing the core mission of HEIs, i.e. how institutions are and will be funded, how training will be delivered, how findings from research will be disseminated and applied and what matters for successful performance assessment exercises. According to Alemán (2014), managerialism advances managers' interests over workers' interests and preserves relations of power and control in the hierarchy of the institution. It is in this context of change that HEIs have been subjected to external pressures to create a new institutional and organisational environment aimed at substituting the collegial model with a managerial one (Carvalho and Santiago 2016).

Along with these shifts, there has also been a trend to replace the election by the nomination as the dominant process to occupy decision-making positions as well as changes in human resources management and assessment exercises. Portugal is no exception to these trends and in 2007 implemented legislation to define a new legal status to HEIs - the RJIES (Law 62/2007). This new legal framework has deeply encapsulated managerialist principles (Diogo and Brückmann 2015; Bruckmann and Carvalho 2014, 2018). In this paper, the authors discuss if and how changes in the governance models and, more specifically, on the way decision-making bodies are constituted in Portuguese HEIs influence the gender balance of their members. Taking that the election, both in the national context and in HEIs, did not prove to provide higher female participation, our hypothesis is that the bodies which are constituted by nomination are more suitable to improve women's participation in academic elite.

The paper is organised as follows: first, the literature on the mechanisms and strategies to improve gender equality in institutional decision-making processes and bodies is reviewed, following which the institutional governance structure in Portuguese HEIs is presented. Subsequently, the methodology used for the study is described in more detail, and, finally, research findings are reported and discussed, and their implications for further research are highlighted.

\section{Mechanisms to improve gender equality in institutional decision-making processes and bodies}

At the beginning of the millennium, and similarly to other institutions and organisations, HEIs have been facing increasing pressures to institutionalise strong managerial modes of operation and leadership. NPM and managerialism provide fertile soil for HEI become subjected to external pressures in order to create a new institutional and organisational environment aimed at substituting the collegial model of governance with a managerial one (Carvalho and Santiago 2015; Shepherd 2017; White et al. 2011; Amaral and Meek 2003; Veltri and Puntillo 2019), increasing the pressure on international control mechanisms (Veltri and Puntillo 2019).

The influence of managerialism turned HEIs more like corporates, being assumed not as institutions but as organisations (Santiago et al. 2006). There is a discussion in the literature on the potential impact of managerialism on gender equality in higher education. While some defend that managerialism may improve women's situation since it turns performance assessment more objective; others consider that 
it brings even more difficulties for women to reach the top and to participate in institutional bodies of decision-making (Teelken 2012; White, Carvalho, and Riordan 2011). Previous research confirmed that those with a non-permanent position tend to assume teaching duties almost exclusively, with a heavy workload (Gale 2011; O'Connor 2015); teaching duties tend to be mainly performed by women (Carvalho and Diogo 2018a; Acker and Dillabough 2007; Angervall et al. 2015), transforming these individuals into what Angervall and Beach (2018) labelled of "profitable workers". As Burkinshaw and White (2017) refer to, being a minority creates precariousness in itself. In fact, women in universities (as well as other minority groups who work part-time and on a temporary basis) face increasingly precarious career paths due to job insecurity, managerialist practices, heavy workloads and they even are paid less (Bagilhole and White, 2011; White et al. 2011; El-Alayli et al. 2018; Fogg 2003; Gentry and Stokes 2015; Carvalho and Diogo 2018a; Barrett and Barrett 2011; Aarrevaara et al. 2007). When analysing the differential effects of academic capitalism on academic women, Metcalfe and Slaughter (2008) acknowledged that female academics end up in a disadvantageous position in academia as managerialism reorganises professional power and privilege in a way that academic advancement is secured through market-based criteria, compromising academic capitalism. Also regarding the reality in the United States, Alemán (2014) refers that the adoption of managerialism in US universities, overvaluing and intensifying managerial principles, led to the strengthening of discursive masculinity and worsened women's faculty likelihood of professional advancement endangering gender equity in the academic profession.

In this sense, the literature is also consistent with the fact that although managerialism in higher education can provide opportunities for women to develop their careers-especially for those that can be successful in obtaining funding-it also perpetuates and intensifies the gendered organisational culture (Acker 1990; Acker and Dillabough 2007; Acker et al. 2012; Vickers 2011; Thomas and Davies 2002; Blättel-Mink et al. 2012; Davies and Thomas 2002) as socioeconomic and ideological forces shape gender/power relation (Hearn and Husu 2011; Vickers 2011; Archer 2008; Peterson 2016). In parallel, there are also some studies revealing how NPM and managerialism can benefit women since institutions are expected to be more accountable, objective and reliable on performance indicators, which could turn more visible the work made by women (Morley 2013; O'Connor and O'Hagan 2016; O'Connor and White 2011; Stefani and Blessinger 2017; O'connor 2014).

Towards this reality, and in order to understand gender and its implications for academic elite, we assume that the objectivity and accountability assumed by NPM and managerialism can improve women's presence in relevant governance bodies. The constitution of the governance bodies in the previous collegial model was mainly based on the election process. This, along with the experience with the national elections, demonstrates that this system does not provide high female participation. Furthermore, there is a recurrent argument that few women are willing to participate in governance bodies due to work-family balance, turning more difficult their inclusion in the elections' list. However, the selection process for nomination is expected to be based on meritocracy. The nomination has as its main purpose to improve the quality of the team, and, ultimately, institutional decisions (Ruigrok 
et al. 2006). Since NPM and managerialism open the opportunity to turn women's merit and excellence more visible, it is also expected that it may increase their chances to be nominated. Nevertheless, we also know that science and technology are not just structured by gender but pervaded and constituted by and through gender, gender relations and gendered power relations (Hearn and Husu 2011). This means that people, academics in this context, are not prepared to see (or to live with) the presence of women in executive positions, but rather that there is a lack of gender awareness in organisations (Hearn and Husu 2011). For example, the Portuguese case exemplifies that despite the changes in national laws promoting gender equality in society, and the high participation of women in higher education, it was only in 2001 that the first woman rector was elected, and since then, only six more in the whole country have achieved this position (Carvalho and Diogo 2018b). This resonates with that of Espírito-Santo (Espírito-Santo 2016) on the Portuguese citizens' attitudes towards women in parliament. According to her study, the Portuguese population is willing to see an increase in the number of women in political power, but only up to a certain point. This is so because even though most people support an increase in the number of female Prime Ministers, only a minority wishes a substantial increase. Taking this general tendency, one can expect that when bodies are constituted by election women have fewer opportunities to occupy the positions, while when they are occupied by nomination their probability increases. However, the lack of gender awareness may reproduce the same tendencies to nominate men for elite positions.

Although with interesting specificities (Amâncio and Ávila 1995), the Portuguese scenario does not differ much from the general trends presented above, being therefore relevant to understand whether NPM and managerialism and more specifically the way the bodies are constituted eased up or hindered women's presence in decision-making bodies.

\section{Shifts in institutional governance structures in Portuguese HEls}

The literature on higher education governance is consistent with the fact that NPM and managerialism have produced pressures to create a new institutional and organisational environment, aiming at substituting the collegial model with a managerial one (Meyer and Hammerschmid 2006; Santiago et al. 2006; Shepherd 2017; Veltri and Puntillo 2019; Bruckmann and Carvalho 2014). Drivers for change on higher education systems and institutions claim for more effectiveness and efficiency, more flexibility at the level of the organizational structures, the benefits of bringing into public institutions private sector management models, contracting-out, markets or 'quasi' markets, accountability and increased decision-making power roles (Carvalho and Santiago 2010; Diogo and Brückmann 2015; Bruckmann 2017). In Portuguese higher education, these changes were incorporated by Law 62/2007 (RJIES), which stipulated the new legal framework for HEIs, leading to governance and statutory changes in HEI. Among changes in the universities' organisational structure, we highlight the following: 
Table 1 Universities' governance structures before and after the reform introduced by Law 62/2007 (RJIES) Source: Adapted from Bruckmann (Bruckmann 2017)

\begin{tabular}{lll}
\hline $\begin{array}{l}\text { Governance structures before RJIES } \\
\text { (defined by Law 108/88) }\end{array}$ & \multicolumn{2}{l}{ Governance structures after RJIES (defined by Law 62/2007) } \\
\cline { 2 - 3 } & Public institute universities & Foundation universities \\
\hline Rector & Rector & Board of Trustees \\
Academic/University & General Council & Rector \\
Senate University Assembly & Management Board & General Council \\
Administrative Council & & Management Board
\end{tabular}

- Fewer government bodies and a reduction in the number of members who constitute them. Simultaneously, there were changes in their composition through a greater intervention by civil society, including external stakeholders, resulting, thereby, in less representative boards and increasingly more professional ones in terms of institutional management and stronger leadership. For example, boards like the academic senate, which has a long tradition in universities' governance models, and the university assembly ceased to be mandatory and the choice to have a Senate is left to the institution. The main mandatory and executive boards are now the General Council, the Rector, and the Management Board, and foundation universities add the Board of Trustees.

- Concentration of power in single-person executive bodies. As Bruckmann (2017) explains, the Rector is a single-person body, who has seen his/her powers greatly enhanced after the reform. S/he no longer depends on decisions taken by an academic senate composed by a great number of academics to decide upon important matters, as s/he can decide for her/himself and, therefore, is also responsible for the decisions s/he takes. This is considered a more efficient way of governing a university, as the process of decision-making is streamlined, but it changes the long-standing collegial paradigm in universities' governance models (Bruckmann 2017; Diogo 2015).

- A switch from election as the single selection mode of board members to the introduction of appointment and co-option as possible and sometimes mandatory selection modes, as well as a change from a direct election for single person executive bodies into an indirect election by board members instead of by all actors from academia (Diogo and Brückmann, 2015; Bruckmann 2017). ${ }^{1}$ In fact, the replacement of the election by the nomination became the dominant process to occupy decision-making positions. For example, before Law 62/2007 (RJES), rectors used to be elected by the university assembly. Now they are elected by secret ballot by the General Council. This modification does not change the rector's basic functions as the law stipulates that s/he be the General Council's sen-

\footnotetext{
${ }^{1}$ Law 62/2007 also promotes initiatives for transforming the funding system into performance-based funding while introducing accountability.
} 
ior official. Additionally, universities were given the choice to either remain pub-

lic institutes or become a public foundation operating under private law.

Table 1 summarises the changes at universities before and after RJIES, presenting the mandatory governance boards, before and after the 2007 reform, and comparing these governance bodies in universities that remained public institutions with those that changed their legal status to public foundations under private law, as it is the case of the university analised in this study. Law 62/2007 stipulated fewer governance bodies with fewer people: instead of having four organs, sometimes universities were left with only three, in which case the university assembly was replaced by a smaller General Council. This has implied an excessive concentration of power in universities' General Councils and sole proprietorship positions, i.e. rectors and directors of polytechnics, and Deans, meaning that researchers, students, and staff feel a significant reduction in the academic endeavour as well as lower participation in democratic governance (Diogo and Brückmann 2015). This new paradigm of governance-not always accepted smoothly-is thus very much in line with NPM and managerialism principles.

As aforementioned, the appointment performed by the General Council replaced election as the selection method of the Rector, who, in turn, appoints the Management Board and chairs it. Regarding the General Council, there are university estate representatives, who are elected from among their peers, and lay members, who are co-opted based on their individual skills, not acting as representatives. In addition, the foundational model envisages an extra collegial governing body-the Board of Trustees-composed of five members appointed by the government upon the institution's suggestion.

This information is important to understand how decision-making bodies have been changing, their mission and how they are constituted so that it is possible to assess whether gender balance in decision-making bodies is influenced or not by the way they are constituted.

\section{Methodology}

The main purpose of this paper is to understand if and how the way decision-making bodies are constituted, influence the gender balance of their members. In parallel, information on what may increase or decrease the number of 'women in governance' is also put forward as the objective guiding this study is to understand the relationships between the way the universities' governance bodies are constituted and the number of women integrating them.

In order to accomplish our aim, quantitative and qualitative approaches were triangulated (cf. Tables 2, 3, 4 and 5). As Campbell (1974) puts it, triangulation strengthens a study by combining methods. The four basic types of triangulation identified by (Denzin 1978 in Patton 2002) were used in this study: (i) data triangulation (the use of a variety of data sources) in the study; (ii) investigator triangulation (having several researchers elaborating the study. The authors are (three) researchers with different backgrounds and professional paths); (iii) theory 
Table 2 Summary of Interviewees' Profile

\begin{tabular}{llll}
\hline & Women & Man & Total \\
\hline $\begin{array}{l}\text { Top-Management (governance structures, i.e. Rector; Univer- } \\
\text { sity Assembly; etc.) }\end{array}$ & 1 & 2 & 3 \\
Middle Management (management bodies, i.e. Deans) & 1 & 2 & 3 \\
Academics (non-management or governance structures) & 3 & 0 & 3 \\
$\begin{array}{l}\text { Technostructure (administrative staff) (non-management or } \\
\text { governance structures) }\end{array}$ & 2 & 1 & 3 \\
Total & 7 & 5 & 12 \\
\hline
\end{tabular}

triangulation (the use of multiple perspectives to interpret our data) and (iv) methodological triangulation (the use of multiple methods to study a problem).

Quantitative and qualitative data were obtained through several stages. Data about the gender constitution of the decision-making bodies of all 14 Portuguese public universities and the processes of accessing these bodies-elections vs. nomination-were scrutinised through consultation of universities' websites (cf. Table 3). Table 3 highlights the female participation in Portuguese universities' governance structures, segregating data according to both the election and the nomination procedures. This was then cross-compared with an in-depth analysis of the university selected as a case study (cf. Tables 4 and 5). The authors have thus analysed how many bodies have their members elected and how many bodies have their members nominated, and how many of these are women, in order to assess if there are differences in the gender constitution. This is combined with qualitative data focusing on the content analysis of legal documents describing the mission of the decisionmaking bodies, as well as their importance towards the mission and objectives of the university (cf. Table 5), plus on twelve interviews with institutional key-actors of the case-study institution.

The interview guideline follows the established protocol applied to the six-country research teams that constitute the CHANGE project consortium (Austria, Slovakia, Israel, Germany, Portugal, and Slovenia) in order to enhance comparison. Briefly put, this project (H2020 funded) aims at implementing a Gender Equality Plan (GEP) in research performing organisations. In-depth interviews to scrutinise key-institutional actors' views on gender equality and inclusive working environments were carried out at an initial stage of the project. For this study, we focused mostly on those parts related to the explaining factors for the (non)presence of 'women in governance'. Interviews were tape-recorded and transcribed and interviewees were informed of the main purpose of the study with data anonymity being assured. Interviewees' identification according to their sex and role/position they hold in the university is presented in Table 3.

The framework used to analyse data from this case study lays in the combination of the above literature review, which introduced the theoretical framework, with the analysis of the legal documents on the decision-making bodies and the interviews' analysis process. Interview themes were coded through the help of the data analysis software Nvivo, thus thematic analysis was undertaken in the light of the themes 


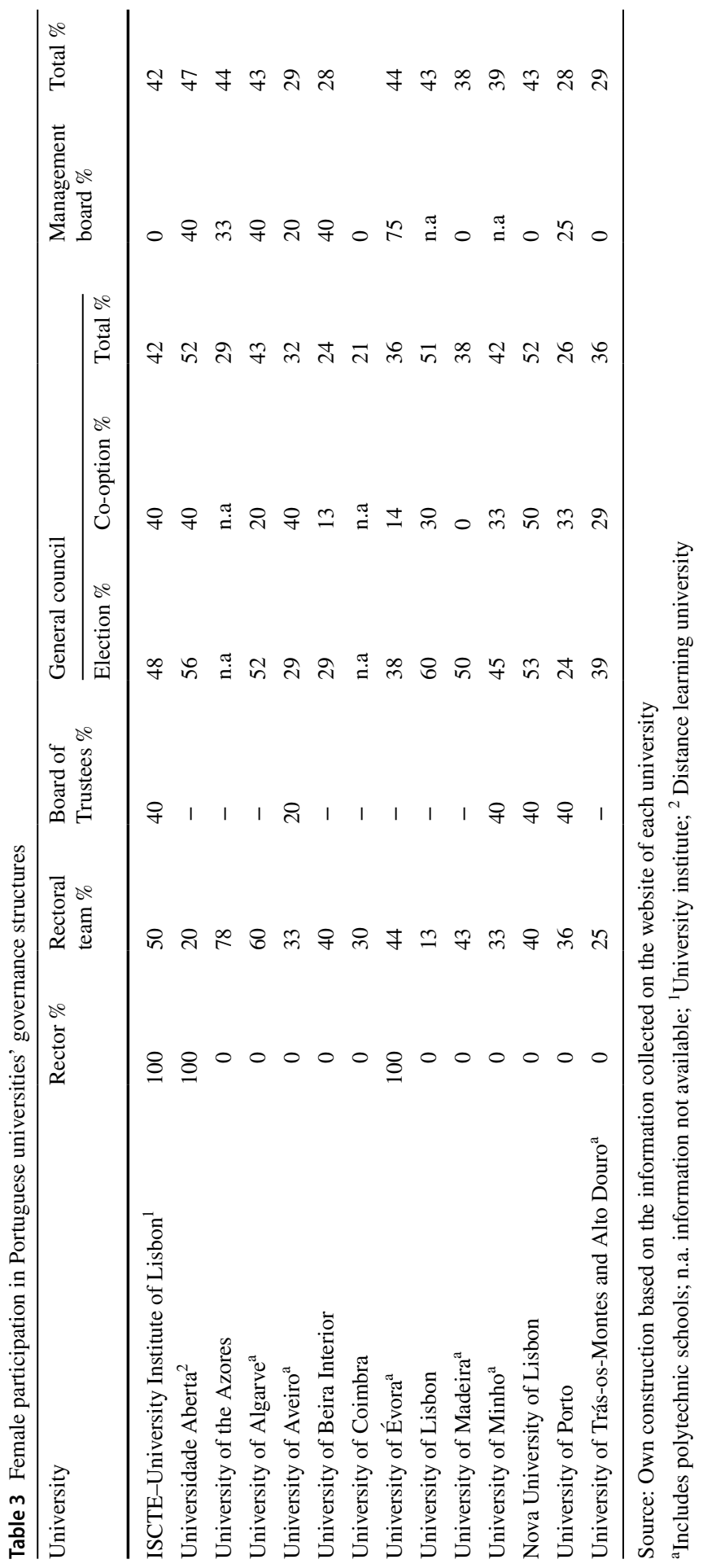


Table 4 Gender Composition of the UAVR bodies (by percentage and number)

\begin{tabular}{|c|c|c|c|c|c|}
\hline & Men & $\%$ & Women & $\%$ & Total \\
\hline \multicolumn{6}{|l|}{ Governance bodies } \\
\hline Rector & 1 & 100 & 0 & 0 & 1 \\
\hline Rectoral team & 8 & 67 & 4 & 33 & 12 \\
\hline Board of trustees & 4 & 80 & 1 & 20 & 5 \\
\hline General council & 13 & 68 & 6 & 32 & 19 \\
\hline Elected: & 10 & 77 & 4 & 29 & \\
\hline Co-opted: & 3 & 23 & 2 & 40 & \\
\hline Management board & 4 & 80 & 1 & 20 & 5 \\
\hline Total & 30 & 71 & 12 & 29 & 42 \\
\hline \multicolumn{6}{|l|}{ Scientific and pedagogic bodies } \\
\hline Scientific council & 11 & 44 & 14 & 56 & 25 \\
\hline Pedagogical council & 13 & 54 & 11 & 46 & 24 \\
\hline Total & 24 & 49 & 25 & 51 & 49 \\
\hline \multicolumn{6}{|l|}{ Management bodies } \\
\hline Deans & 16 & 80 & 4 & 20 & 20 \\
\hline Executive commission & 49 & 56 & 39 & 44 & 88 \\
\hline Coordinators of research units & 15 & 75 & 5 & 25 & 20 \\
\hline Total & 80 & 62.50 & 48 & 37.50 & 128 \\
\hline \multicolumn{6}{|l|}{ Advisory bodies } \\
\hline Council of ethics & 8 & 75 & 4 & 25 & 12 \\
\hline Disciplinary commission & 5 & 71 & 2 & 29 & 7 \\
\hline Student ombudsman & 0 & 0 & 1 & 100 & 1 \\
\hline Total & 15 & 75 & 5 & 25 & 20 \\
\hline
\end{tabular}

previously chosen by the authors and that have emerged from the combination of all these sources. It is expected that this research design will enable the generalisation of findings to different groups and geographical settings. The discourses analysed-with few exceptions-strongly resonate with the 'fixing the women' perspective, as evidenced in the following section.

\section{Data analysis and discussion}

In order to understand if the process of constituting the governance bodies interfere with the gender composition of the elite academics in Portugal, the most relevant bodies were chosen to be analysed in all public universities. The Portuguese state higher education system comprises 14 universities (including one public university institute and one distance learning institution), being all analysed to determine the ratio of women in their governance bodies. Since the definition of academic elite is rather broad, including persons in formal outstanding university positions (Rogg 2003) a decision was made to include all the relevant bodies for which public data 


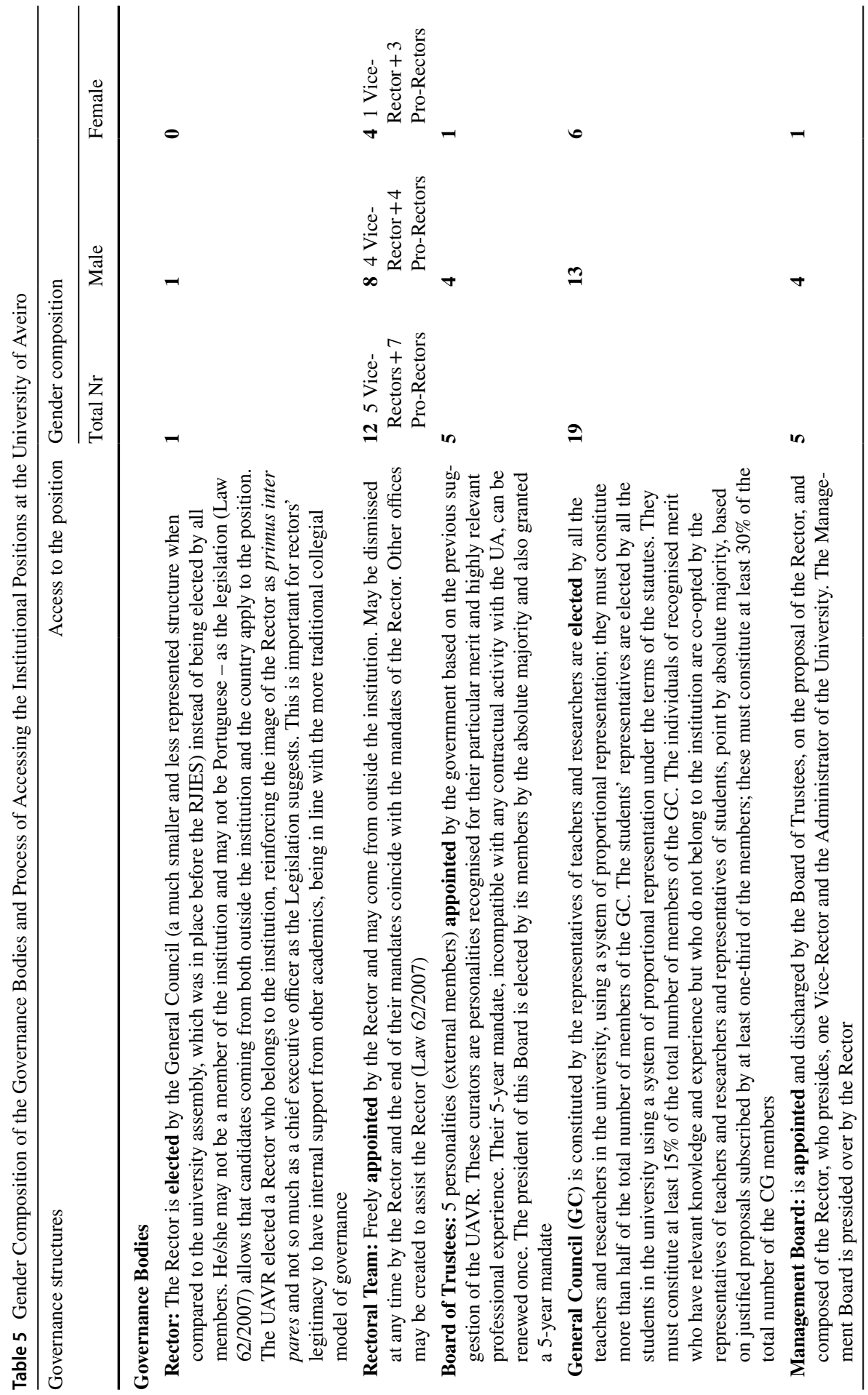




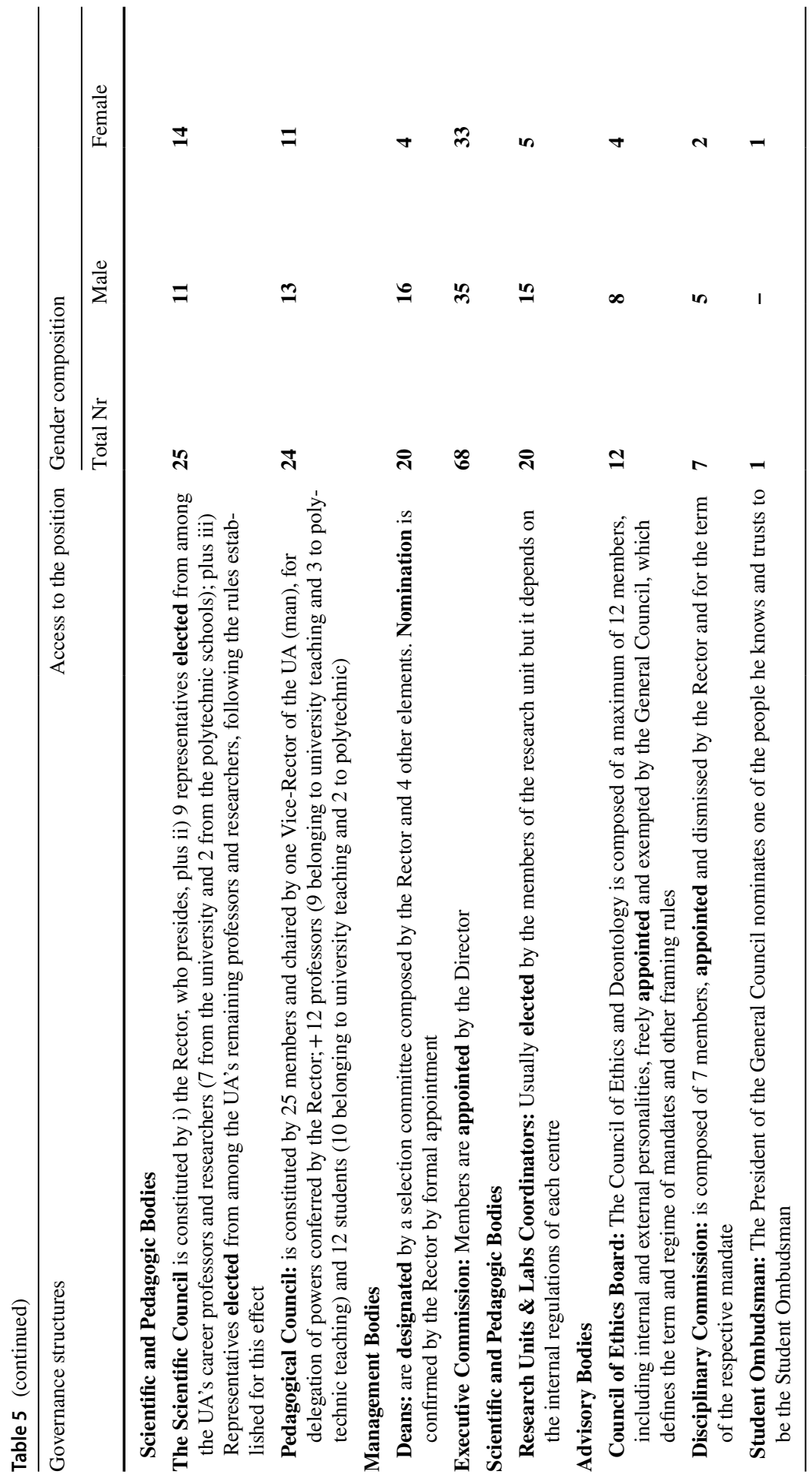


was available-Rector, Rectoral Team, Board of Trustees, General Council and Management Board (cf. Table 3). Other bodies, located at an intermediated (middle management) level (scientific and Pedagogical Council and Deans), were excluded since data was not available. However, the specific analysis of the University of Aveiro also includes these bodies.

Gathered data indicate that within the top decision-making bodies there is a fairly small percentage of women reaching the highest academic positions. As the rector is a single-person body it is relevant to see that only three universities in 14 have a woman leader. Furthermore, there is no clear relation between having a woman rector and having more women in other decision-making bodies.

The analysis of the other decision-making bodies reveals that women are still absent from the academic elite. Concerning the rector team, only in three universities women represent, at least, half of the members. In most of them, the percentage of women is between 20 and $40 \%$. This is particularly relevant, considering that it is usually from this small team that the next rector is chosen. In the management board, only one university has more than $50 \%$ of women in its constitution. So, it seems that the representation of women is even smaller at the leading positions with higher financial authorities and control over relevant decisions. Taking all the bodies it is possible to conclude that women are always less than $50 \%$ of elite academics. The university that has a higher proportion of women is the Universidade Aberta, which is a distance learning university with a great number of degrees in social sciences and humanities.

Under-representation of women is clearly expressed in all bodies, independently from the way members are gathered. On contrary to what was expected, even in the bodies which are constituted by nomination, as the rectors' team, the proportion of women is not higher. Particularly interesting is the analysis of the General Council. As previously explained, this council is constituted by university members, who are elected, and external members who are co-opted. In the majority of the cases, the co-opted members have a low proportion of women but this is also true, in the majority of the cases, for the elected members.

In order to try to deepen the analysis, the specific case study of the University of Aveiro was developed. This university was chosen since it was the first university, in Portugal, to have a woman rector, which may translate the existence of a greater gender awareness in the institutional culture (Carvalho and Diogo 2018b).

The Portuguese university of this case-study works as an excellent case-study to analyse and test such relationships and processes. A first glance to Table 4 immediately confirms what the literature and statistical data refer to the reduced number of women achieving senior or top leadership positions in academia: they represent a considerably smaller percentage when compared to men.

However, and in addition to this, it is still not clear the relationship between the process of reaching the institutional position/role and their gender composition. In other words, we are interested in testing the hypothesis if there are differences in the gender composition of the institutional bodies according to the process of accessing these bodies: election vs. appointment. In order to clarify the process for each body in this university, as well as their mission, content analysis of institutional documents was developed (cf. Table 5). 
Being it a foundation university, the University of Aveiro is steered by a Board of Trustees composed of five personalities of high merit and professional experience recognised as especially relevant for the University. They are appointed by the Government upon the University's proposal and the president of this Board is elected by its members-mostly men (cf. Table 5). The performance of the University's leader-the Rector-is supervised by this Board of Trustees, of which the great majority are constituted by men. A similar situation happens with the Rectoral Team who is freely appointed by the Rector and it is constituted by the double of men (8) than women (4), and the General Council, also constituted by more men than women, and which is also one of University's executive boards. The General Council appoints the Council of Ethics - constituted by 9 men and 3 women, and the Student Ombudsman (1 man). As a matter of fact, in this university, different bodies have a highly relevant role in adopting and change general acts (e.g. the statutes), namely the General Council. In these bodies, one finds representatives of different groups of stakeholders (both internal and external to the academia). Also, the Executive Commission and the Disciplinary Commission (an advisory board) are constituted by significantly more men than women and their members are also appointed-by the Director/Deans-in the case of the Executive Commission, and by the Rector, as it is the case of the Disciplinary Commission.

The analysis of the composition and mission of the main mandatory and executive boards of the institution reveals vertical segregation-as the number of men and women in these bodies is not equitable. In fact, only at the Scientific Council, the body that takes decisions concerning the University's scientific activities and scientific policies, there is gender parity. Within the scientific and pedagogic bodies, i.e. the bodies responsible for the scientific and pedagogical decisions at the strategic and/or operational levels one can also observe gender imbalance regarding their composition, although not as high as it happens with the highest governance bodies of the institution. Still, concerning the Pedagogical Council, for example, responsible for the university educational affairs, more men than women constitute it.

It should be noticed that at the Scientific Council-as well as for the Pedagogical Council and the General Council, members are elected and not appointed as it happens in the case Rectoral Team, the Board of Trustees, the Management Board, and the Executive Commission. For the exception of the Scientific Council, it is reckless to affirm that there is a direct relation between election vs. appointment and gender parity. Nevertheless, the specific analysis of this case study is particularly relevant since it demonstrates that as the importance of the decision-making body increases, the presence of women decreases. As a matter of fact, and interesting enough is that the Rector, the president of the General Council, the president of the Board of Trustees and the president of the Management Board are men... It is thus of paramount importance to analyse why women are so underrepresented in these bodies. Are they not available or willing to integrate these bodies or/and are there any other factors that condition their presence (or the lack of it)? Trying to understand this fact, a series of interviews (12) to institutional key-actors (Table 2) were conducted.

Generally speaking, the dominant perspective is that the problem lies in the women themselves who do not have or manifest interest in these positions. As the 
following citation evidence, most of our females' discourses show alignment with the perspective 'the problem is women':

I acknowledge that mentalities need to change, but women should also empower themselves, asserting themselves, emerging as leaders! If women stand for what they want, they will (eventually) obtain it (woman, top-management $2^{2}$ ).

Consequently, these messages contribute to perpetuating the situation of women under-representation at the highest executive governance bodies, as the feeling portrayed is that women who really want to become institutional leaders or managers will do it. Being a relatively small institution, it is thus natural that these visions become known and incorporated by those who appoint the institution representatives and the members of the governance bodies. Nevertheless, other interviewees reveal how even if they did not think of becoming members of these bodies, they feel they fit in.

Actually, it was quite unexpected. I was chosen (appointed) rather than elected because the former Director quit the job. The Rector appointed me until the term of office of the previous Director, also because I was already a member of the Executive Commission/Committee (Executive Board). I never thought of applying for this job (woman, middle-management 4).

Although she refers that it was completely unexpected and that she has never thought about it before, she did not refuse the job and feels that she was, in fact, the best decision the Rector could make. She sees herself as a good leader, regardless of her sex, assuming this leadership experience as gender-neutral.

Now I am enjoying it and I think I am a good leader, regardless of being a woman. At least I like to believe that. Among the choices the Rector had, I think I was the best one (woman, middle-management 4).

These discourses signal that-to a great extent-the lack of women in relevant decision-making bodies is also a result of the institutional culture and also of lack of institutional and self-empowerment Actually, the fact that only a few women reach top-positions-and usually at a much later stage than men-seems to be a non-issue for most of our interviewees. From our reduced sample, it is possible to say that interviewees' discourses go against what (Morley 2014) found on the fact of women themselves asserting that they have been marginalised in the gendered research economy.

What seems to be consensual among the interviewees relates to the problem of work overload, of feeling more pressure to be always available and accomplish as much as possible. Such discourses corroborate the NPM credo of strengthening the importance of performativity elements in academics' career development and progression. Although this is a phenomenon common to both genders, especially in a managerial

\footnotetext{
2 The number stands for the order interviews were conducted and to clarify that these views refer to different actors. This was the second interviewee: a woman holding a top-position.
} 
university and research-intensive organisations, it is more penalising for women than men, taking the persistence of a traditional division of roles in the family domain. As reported by both female and male interviewees:

It is something important when we talk about positions that are by nomination, and then we enter the "world of men". Women have a different dedication to family life (although younger generation couples tend to share responsibilities at home) and people in leadership roles believe that women have less availability to be appointed for certain positions. It is more frequent for women than men to refuse certain positions because they do not want to abdicate from their family life. Competency and availability should be articulated and should not exclude each other (man, top-management (3) and women middle-management (5)].

This common perception about leadership roles requiring more time, attention and availability than other roles may explain why women are less present as candidates in formal elections. Nevertheless, contrary to what we expected, the nomination does not seem to clearly improve women's presence in the academic elite. Concomitantly with, or consequently, because of that, women-as well as the institution-automatically excludes or withdraw women from these roles, confirms another hypothesis we wanted to clarify in this study: the increased pressure for quantitative performance and competition tend to favour more men than women. This leads us to a kind of paradox-as the shift of election towards nomination seemed more advantageous for women to assume elite positions in the academic organisational hierarchy, NPM and managerialism practices tend to erode these possibilities for women.

Following Hearn and Husu (2011), it is possible to observe that gender operates in science and technology in a transversal way. The selection for members of the academic elite needs to be analysed under a social embeddedness perspective. Contrary to what was expected, nomination is not able to increase the number of women chosen probably because this is not a rational process as NPM and managerialsim assume. There are a number of social factors influencing the selection process, and gender is one of them. There is bounded rationality-as acknowledged in the literature (Withers et al. 2012). It seems that neither election nor nomination is significantly improving women's presence in the academic elite as women are less available to be candidates for election and they are usually less voted. The nomination may not be the best solution since there may be a tendency to affiliate with those similar (Withers et al. 2012). As a result, even if Portugal stands out among the OECD countries in terms of the percentage of female researchers (OECD 2018), they are still a minority in decision-making bodies. In turn, it can also be argued that nomination (more than election) has contributed to place more women in decision bodies and gradually change the unconscious stereotypes about women.

\section{Conclusions}

By cross comparing the decision-making bodies and processes of all Portuguese public universities and focusing on one Portuguese university governance bodies that have redefined its institutional organisation and legal status as well as their 
constitution, this paper mirrors the operationalisation of a managerial university in terms of gender representation in its governance and management bodies.

The quantitative and qualitative data analysis shows the persistent underrepresentation of women in academic elite. Furthermore, it also reveals how vertical segregation in the case study institution, results in a decrease in gender balance within academia with the increasing importance of the decision-making body. Nevertheless, it is not possible to say that there is a direct relationship between the way actors are chosen to these bodies, i.e. via appointment or election, and their gender balance. In other words, the way actors are chosen can not be seen as the only or most important factor influencing the gender constitution of decision-making bodies, although nomination seems to be more advantageous to women. Institutional culture, gender awareness and even the lack of both self and institutional empowerment are also relevant to understand the low number of women in these positions. The lack of gender awareness and the presence of a dominant masculine culture is evidenced in the interviewees' discourses, who do not perceive the way actors are chosen as a relevant mechanism to improve gender equality, or even a fact to consider in this domain. A possible explanation for this may be the fact that universities are still seen as gender-neutral, despite the gender is embedded in HEIs structures, processes, and cultures. Gendered power relations are thus (still) important characteristics of higher education and science and technology systems. Towards this scenario, this study provides a relevant contribution to the literature on mechanisms to improve gender equality in institutional decision-making processes and bodies, as well as to raise gender awareness within HEIs. In fact, and generally put, a kind of paradox seems to emerge as referred earlier: while changes in governance modes, namely the shift of election towards nomination, seem more prone or more advantageous for women to assume elite positions in the academic organisational hierarchy, NPM and managerialism practices tend to erode these achievements.

Nevertheless, this paper is based on an in-depth case study and more research needs to be developed-and a multi-theoretical approach-to assess how managerialist practices, NPM ideology, and governance procedures affect the gender constitution of governance bodies, also in other types of HEIs (e.g. private ones and technical/ vocational institutions) and in other geographical settings.

Acknowledgement The authors of this paper would like to thank the interviewees who gently contributed to this study as well as to the CHANGE project. This work was financially supported by the Horizon 2020 Project (H2020-SwafS-2016-17-Science with and for Society) CHANGE - CHAlleNging Gender (In)Equality in science and research, Grant Agreement ID: 787177, and by POCI-01-0145FEDER-029427- funded by FEDER, through COMPETE2020 - Programa Operacional Competitividade e Internacionalização (POCI), and by national funds (OE), through the FCT/MCTES, Foundtion for Science and Technology (Portugal).

Open Access This article is licensed under a Creative Commons Attribution 4.0 International License, which permits use, sharing, adaptation, distribution and reproduction in any medium or format, as long as you give appropriate credit to the original author(s) and the source, provide a link to the Creative Commons licence, and indicate if changes were made. The images or other third party material in this article are included in the article's Creative Commons licence, unless indicated otherwise in a credit line to the material. If material is not included in the article's Creative Commons licence and your intended use is not permitted by statutory regulation or exceeds the permitted use, you will need to obtain permission directly from the copyright holder. To view a copy of this licence, visit http://creativecommons.org/licen ses/by/4.0/. 


\section{References}

Aarrevaara, T., ARIMOTO, A., Balbechevsky, E., Brennan, J., Graça, M., Harman, G., Higgs, L., Higgs, P., Hölttä, S. \& Locke, W. 2007. The changing conditions for academic work and careers in select countries, INCHER-Kassel, International Centre for Higher Education Research Kassel.

ACKER, J., (1990). Hierarchies, jobs, bodies: a theory of gendered organizations. Gender \& Society, 4, 139-158.

Acker, S., \& Dillabough, J. A. (2007). Women 'learning to labour' in the 'male emporium': Exploring gendered work in teacher education. Gender and Education, 19, 297-316.

ACKER, J., (2009). From glass ceiling to inequality regimes. Sociologie du travail, 51, 199-217.

Acker, S., Webber, M., \& Smyth, E. (2012). Tenure troubles and equity matters in Canadian academe. British Journal of Sociology of Education, 33, 743-761.

ALEMÁN, A. M. M., (2014). Managerialism as the" new" discursive masculinity in the university. Feminist Formations, 26, 107-134.

Amâncio, L. \& Ávila, P. 1995. O género na ciência [Gender in Science]. A Comunidade Científica Portuguesa nos Finais do Século XX [The Portuguese Scentific Community at the end of the XX Century], Oeiras, Celta Editora, 135-162.

Amaral, A., \& Meek, V. L. (2003). The higher education managerial revolution. Berlin: Springer Science \& Business Media.

Angervall, P., \& Beach, D. (2018). The exploitation of academic work: Women in teaching at Swedish universities. Higher Education Policy, 31, 1-17.

Angervall, P., Beach, D., \& Gustafsson, J. (2015). The unacknowledged value of female academic labour power for male research careers. Higher Education Research \& Development, 34, 815-827.

ARCHER, L., (2008). Younger academics' constructions of 'authenticity', 'success' and professional identity. Studies in Higher Education, 33, 385-403.

Bagilhole, B., \& White, K. (2011). Gender, power and management: A cross-cultural analysis of higher education. Berlin: Springer.

Barrett, L., \& Barrett, P. (2011). Women and academic workloads: career slow lane or Cul-de-Sac? Higher Education, 61, 141-155.

BLÄTTEL-MINK, B., MERKATOR, N., KLOKE, K., KRÜCKEN, G. \& SCHNEIJDERBERG, C. 2012. 3) Managing the academia in times of New Public Management-new possibilities for women? Book of abstracts and presentation of keynote speakers, 11.

Bruckmann, S. 2017. Changes in governance and management of higher education institutions in Portugal. PhD Dissertation, Universidade de Aveiro.

Bruckmann, S., \& Carvalho, T. (2014). The reform process of Portuguese higher education institutions: from collegial to managerial governance. Tertiary Education and Management, 20, 193-206.

Bruckmann, S., \& Carvalho, T. (2018). Understanding change in higher education: an archetypal approach. Higher Education, 76(4), 629-647.

Burkinshaw, P., \& White, K. (2017). Fixing the women or fixing universities: Women in HE leadership. Administrative Sciences, 7, 30.

Campbell, D. T. 1974. Qualitative knowing in action research. The Journal of Social Issues.

Campbell, K., \& Vera, A. M. (2010). Female board appointments and firm valuation: Short and long-term effects. Journal of Management \& Governance, 14, 37-59.

Carvalho, T., \& Diogo, S. (2018a). Non-tenured Teachers, Higher Education Encyclopedia of International Higher Education Systems and Institutions. Dordrecht: Springer, Netherlands.

Carvalho, T., \& Diogo, S. (2018b). Women Rectors and Leadership Narratives: The Same Male Norm? Education Sciences, 8, 75 .

Carvalho, T., \& Santiago, R. (2010). Still Academics After All.... Higher Education Policy, 23, 397-411.

Carvalho, T. \& Santiago, R. 2015. Professionalism, Managerialism and Reform in Higher Education and the Health Services: The European Welfare State and the Rise of the Knowledge Society, Palgrave Macmillan.

Carvalho, T. \& Santiago, R. 2016. Transforming professional bureaucracies in hospitals and higher education institutions. Towards A Comparative Institutionalism: Forms, Dynamics And Logics Across The Organizational Fields Of Health Care And Higher Education.

Davies, A., \& Thomas, R. (2002). Managerialism and accountability in higher education: the gendered nature of restructuring and the costs to academic service. Critical Perspectives on Accounting, 13, 179-193. 
DENZIN, N. K., (1978). The research act: A theoretical introduction to sociological methods. New York: McGraw-Hill.

Diogo, S., (2015). Same challenges, different processes: perceptions on governance changes in Portuguese and Finnish higher education. European Journal of Higher Education, 5, 211-225.

Diogo, S. 2016. Changes in Finnish and Portuguese Higher Education Governance: Comparing National and Institutional Responses to the Bologna Process and New Public Management. PhD Monograph, University of Aveiro and University of Jyväskylä

Diogo, S. \& Brückmann, S. 2015. Managing the unmanageable: perceptions on institutional change of a Portuguese university foundation. Working Papers in Higher Education Studies, 1.

Dunn, P., (2012). Breaking the boardroom gender barrier: the human capital of female corporate directors. Journal of Management and Governance, 16, 557-570.

Dunn, D., Gerlach, J. M., \& Hyle, A. E. (2014). Gender and leadership: reflections of women in higher education administration. International Journal of Leadership and Change, 2, 2.

EAGLY, A. H. \& Karau, S. J., (2002). Role congruity theory of prejudice toward female leaders. Psychological Review, 109, 573-598.

El-Alayli, A., Hansen-Brown, A. A., \& Ceynar, M. (2018). Dancing Backwards in High Heels: Female Professors Experience More Work Demands and Special Favor Requests, Particularly from Academically Entitled Students. Sex Roles., 79(3-4), 136-150. https://doi.org/10.1007/s11199-017-0872-6.

Espírito-Santo, A., (2016). Citizens' attitudes towards descriptive representation: The case of women in Portugal. European Journal of Women's Studies, 23, 43-59.

European Commission, EU. 2019. She Figures 2018. Retrieved from https://ec.europa.eu/info/publicatio ns/she-figures-2018_en

Fogg, P., (2003). So many committees, so little time. Chronicle of Higher Education, 50, A14.

Gale, H., (2011). The reluctant academic: Early-career academics in a teaching-orientated university. International Journal for Academic Development, 16, 215-227.

Gentry, R., \& Stokes, D. (2015). Strategies for Professors Who Service the University to Earn Tenure and Promotion. Research in Higher Education Journal, 29, 1-13.

Hearn, J., \& Husu, L. (2011). Understanding Gender: Some Implications for Science and Technology. Interdisciplinary Science Reviews, 36, 103-113.

Metcalfe, a. \& Slaughter, S. 2008. The differential effects of academic capitalism on women in the academy. Unfinished agendas: New and continuing gender challenges in higher education, 80-111.

Meyer, R. E., \& Hammerschmid, G. (2006). Changing institutional logics and executive identities: a managerial challenge to public administration in Austria. American Behavioral Scientist, 49, 1000-1014.

Morley, L. (2013). The rules of the game: women and the leaderist turn in higher education. Gender and education, 25, 116-131.

Morley., L. (2014). Lost leaders: Women in the global academy. Higher Education Research and Development, 33, 114-128.

O'connor, P. (2014). Management and Gender in Higher Education. Oxford: Oxford University Press.

O'Connor, P., \& O'Hagan, C. (2016). Excellence in university academic staff evaluation: a problematic reality? Studies in higher education, 41, 1943-1957.

O'Connor, P. (2015). Management and gender in higher education. Manchester: Manchester University Press.

O'Connor, P. 2018. Introduction to special issue on gender and leadership and a future research agenda. Multidisciplinary Digital Publishing Institute.

O'Connor, P., \& White, K. (2011). Similarities and differences in collegiality/managerialism in Irish and Australian universities. Gender and Education, 23, 903-919.

OECD. 2017a. The Pursuit of Gender Equality: An Uphill Battle [Online]. Paris: OECD Publishing. https://www.oecd-ilibrary.org/social-issues-migration-health/the-pursuit-of-gender-equality_97892 64281318-en 2018.

OECD 2017b. Report on the Implementation of the OECD gender recommendations - some progress on gender equality but much left to do. Meeting of the OECD council at ministerial level. Paris: Organisation for Economic Cooperation and Development.

OECD. (2018). Review of the Tertiary Education. Paris: Research and Innovation System in Portugal.

Patton, M. Q. 2002. Qualitative research and evaluation methods. Thousand Oaks. Cal.: Sage Publications.

PETERSON, H., (2016). Is managing academics "women's work"? Exploring the glass cliff in higher education management. Educational Management Administration and Leadership, 44, 112-127. 
Powell, G. N., \& Greenhaus, J. H. (2010). Sex, gender, and the work-to-family interface: Exploring negative and positive interdependencies. Academy of Management Journal, 53, 513-534.

Reskin, B. F., \& Roos, P. A. (1990). Job Queues, Gender Queues: Explaining Women's Inroads into Male Occupations. Philadelphia, PA: Temple University Press.

ROGG, E. 2003. The Structure of Academic Elite in Norway. Gender and Power in the New Europe, the 5th European Feminist Research Conference, August 20-24, Lund University, Sweden. https://cdn. atria.nl/epublications/2003/Gender_and_power/5thfeminist/paper_561.pdf.

Ruigrok, W., Peck, S., Tacheva, S., Greve, P., \& Hu, Y. (2006). The Determinants and Effects of Board Nomination Committees. Journal of Management and Governance, 10, 119-148.

Ryan, M. K., \& Haslam, S. A. (2005). The glass cliff: Evidence that women are over-represented in precarious leadership positions. British Journal of Management, 16, 81-90.

Santiago, R., Carvalho, T., Amaral, A., \& Meek, V. (2006). Changing patterns in the middle management of Higher Education Institutions: the Case of Portugal. Higher Education, 52, 215-250.

Santia, L. (2000). Has feminism changed science? Signs: Journal of Women in Culture and Society, 25, 1171-1175.

Shepherd, S. 2017. Managerialism: an ideal type. Studies in Higher Education, 1-11.

Stefani, L., \& Blessinger, P. (2017). Inclusive leadership in higher education International perspectives and approaches. Abingdon: Routledge.

Teelken, C. (2012). Compliance or pragmatism: How do academics deal with managerialism in higher education? A comparative study in three countries. Studies in Higher Education, 37, 271-290.

Thomas, R., \& Davies, A. (2002). Gender and New Public Management: Reconstituting Academic Subjectivities. Gender, Work \& Organization, 9, 372-397.

Veltri, S., \& Puntillo, P. (2019). On intellectual capital management as an evaluation criterion for university managers: a case study. Journal of Management \& Governance, 24, 135-167.

Vickers, J. 2011. Gender and State Architectures: The Impact of Governance Structures on Women's Politics. Politics and Gender, 7, 254-262.

Wieland, S., \& Flavel, B. (2015). The influence of gender diverse corporate boards on employee-orientation. Journal of Management \& Governance, 19, 825-848.

Withers, M. C., Hillman \&, A. J., A. A., \& Cannella JR, (2012). A multidisciplinary review of the director selection literature. Journal of Management, 38(1), 243-277.

White, K., Carvalho, T., \& Riordan, S. (2011). Gender, power and managerialism in universities. Journal of Higher Education Policy and Management, 33, 179-188.

Publisher's Note Springer Nature remains neutral with regard to jurisdictional claims in published maps and institutional affiliations.

\section{Affiliations}

\section{Sara Diogo ${ }^{1,2,3}$ (D) . Teresa Carvalho ${ }^{1,2} \cdot$ Zélia Breda $^{3,4}$}

Teresa Carvalho

teresa.carvalho@ua.pt

Zélia Breda

zelia@ua.pt

1 Department of Social, Political and Territorial Sciences, University of Aveiro, Aveiro, Portugal

2 CIPES - Research Center on Higher Education Policies, Matosinhos, Portugal

3 GOVCOPP - Research Center on Governance, Competitiveness and Public Policies, University of Aveiro, Aveiro, Portugal

4 Department of Economics, Industrial Engineering, Management and Tourism, University of Aveiro, Aveiro, Portugal 